\title{
Erratum to: Mitigation of Salt Stress Negative Effects on Sweet Pepper Using Arbuscular Mycorrhizal Fungi (AMF), Bacillus megaterium and Brassinosteroids (BRs)
}

\author{
Amira M. Hegazi ${ }^{1}$ Amal M. El-Shraiy ${ }^{1}$ A. A. Ghoname ${ }^{2}$
}

Published online: 23 May 2017

(c) Springer-Verlag Berlin Heidelberg 2017

\section{Erratum to:}

Gesunde Pflanzen, May 2017

DOI: 10.1007/s10343-017-0393-9

The original version of this article unfortunately listed the author's names as "A. M. Hegazi” and "A. M. El-Shraiy".

The correct author's names are Amira M. Hegazi and Amal M. El-Shraiy.

The original article has been corrected.

The publisher would like to apologise to the author for this error and the inconvenience caused.

Conflict of interest A.M. Hegazi, A.M. El-Shraiy and A.A. Ghoname declare that they have no competing interests.

The online version of the original article can be found under doi: 10.1007/s10343-017-0393-9.

Amira M. Hegazi

amirahegazi@yahoo.com

1 Agric. Botany Department, Faculty of Agriculture, Ain Shams Univ., Cairo, Egypt

2 Vegetable Research Department, National Research Center, Dokki, Cairo, Egypt 